\title{
Effects for Charge Transfer in Pd(II) Complexes along Various Terminal Ligands
}

\author{
Mahreen Arooj, Kyungok Park, ${ }^{\dagger}$ and Jong Keun Park* \\ Department of Chemistry Education, Research Institute of Natural Science and Educational Research Institute, \\ Gyeongsang National University, Jinju 660-701, Korea. *E-mail: mc7@gnu.ac.kr \\ ${ }^{\dagger}$ Samsung Advanced Technology Training Institute, HRD Center, Samsung Electronics, Korea \\ Received July 2, 2010, Accepted October 6, 2010
}

Key Words: Charge transfer, Heterocyclic compound, Pd(II) complex, DFT

Heterocyclic compounds such as thiophene and selenophene with their plane $\pi$-conjugated structures are of immense interest as they give rise to wide range of applications. ${ }^{1}$ The charge variations of $\mathrm{X}(\mathrm{X}=\mathrm{S}, \mathrm{Se})$ on the bridging ligand in $\mathrm{Pd}(\mathrm{II})$ metal complexes were influenced by the electron donating and/or withdrawing groups at the terminal ligands. Many researchers have used variety of electron-rich or electron-deficient substituent which induces intra-molecular interactions thus controlling the geometry of the structures. ${ }^{2-3}$ Therefore, rendezvous of suitable substituent is an important factor that can influence the intra-molecular geometry of the complexes via atomic charge variations between various substituents. Phetmung et al. indicated the significant character of the S $\cdots \mathrm{S}$ inter- and intra-molecular interactions in controlling the reactivity of sulfur compounds, the actual conformation, and crystal packing. ${ }^{4}$ In addition, Hayashi et al. reported the $\mathrm{Se} \cdot$. Se contacts in structural and theoretical investigations which stabilized the structures of selenoxides. ${ }^{5}$ In an experimental study, Seppälä group showed the attractive Se $\cdots$ Se interactions between uncharged molecules which lead to the formation of dimmer in supra-molecular structures. $^{6}$

The chalcogen have a strong inclination to act as bridging ligands and a number of bimetallic group 10 complexes with these bridging chalcogen have been characterized. ${ }^{7}$ The main goal of this research work is to theoretically investigate the variation of the atomic charges of $\mathrm{X}$ on bridging heterocyclic ligands along the electron donating and/or withdrawing groups at the terminal ligands. Whether the electron donating and/or withdrawing groups at the terminal ligand instigate modification of the atomic charge of the $\mathrm{X}$ on bridging ligands? Are there any relationship between the electron-property of the terminal ligand and the $(\mathrm{X} \cdots \mathrm{X})$ interaction of inta-bridging ligand? What are the effects of changing heteroatoms from sulfur to selenium? The research work reported here intends to counter all the abovementioned queries.

$\mathrm{Pd}(\mathrm{II})$ complexes having oligothiophene were optimized with 6-31g* for $\mathrm{C}, \mathrm{P}, \mathrm{H}, \mathrm{O}, \mathrm{Cl}, \mathrm{F}$, and $\mathrm{N}$ atoms and LANL2DZ for $\mathrm{Pd}$ atom at the density functional theory (B3LYP) level using Gaussian 03 package. ${ }^{8,9}$ While, $\mathrm{Pd}(\mathrm{II})$ complexes having selenophene as bridging ligand were optimized with $3-21 \mathrm{~g} *$ basis sets at the B3LYP level. Natural Bond Orbital (NBO) analysis was performed in order to investigate the charge distribution in all complexes. To confirm the existence of stable structures, the harmonic vibrational frequencies of the structures were anal- yzed at the B3LYP level. The schematic presentation of the atomic charge transfer in Pd complex in conjunction with the terminal and bridging ligands is depicted in the Scheme 1. The total number of combinations of ligands which are applied as terminal ligand are 11. $\mathrm{Pd}(\mathrm{II})$ complexes can be classified into three types, which are depended upon the kind of terminal ligands as following: A (1 2) complexes with four electrondonating groups at the terminal ligands, B (3 5) complexes with four electron-withdrawing groups, $\mathbf{C}(\mathbf{6} \sim 11)$ complexes with two electron-donating and the other two electron-withdrawing groups. Pd(II) complexes having phosphine-substituted monothiophene, bithiophene, and terthiophene bridging ligands are designated as $\mathbf{a}, \mathbf{b}$, and $\mathbf{c}$, respectively.

Here, we have attempted to find out the influence of terminal ligands which is most suitable in instigating charge transfer and $\mathrm{X} \cdots \mathrm{X}$ distance. As in all $\mathrm{Pd}(\mathrm{II})$ complexes, the variation in terminal ligand environment has shown profound effect on structures of $\mathrm{Pd}$ (II) complexes. Therefore, an investigating piece of property data can be found by changing the atomic charge of $\mathrm{X}$ in $\mathrm{Pd}(\mathrm{II})$ complexes with different terminal ligands. Due to the substitution of terminal ligands of the $\mathbf{A}, \mathbf{B}$, and $\mathbf{C}$ types, the variations of the atomic charge of $\mathrm{X}$ and $\mathrm{X} \cdots \mathrm{X}$ distance has been observed. In optimized Pd(II) complexes, each metal center adopts a square planer geometry in which two positions are

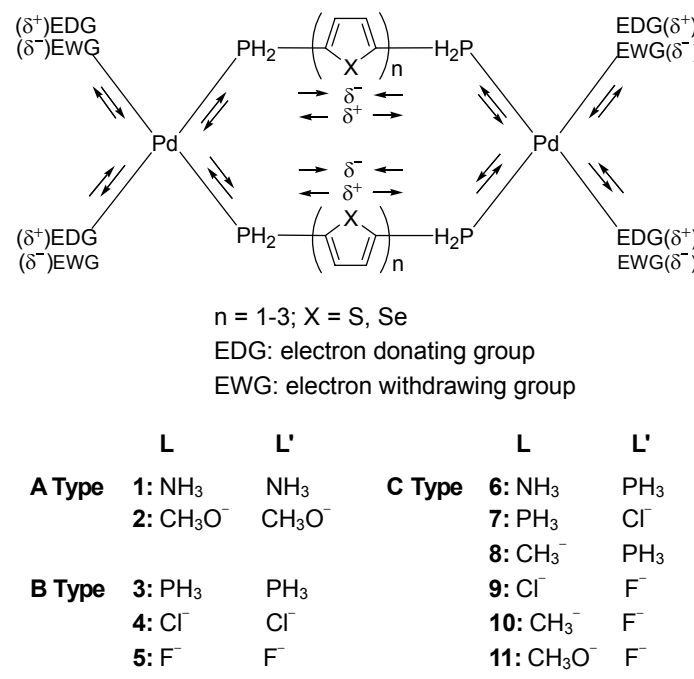

Scheme 1. Schematic diagram of the charge transfer in Pd complex along with terminal and bridging ligands 

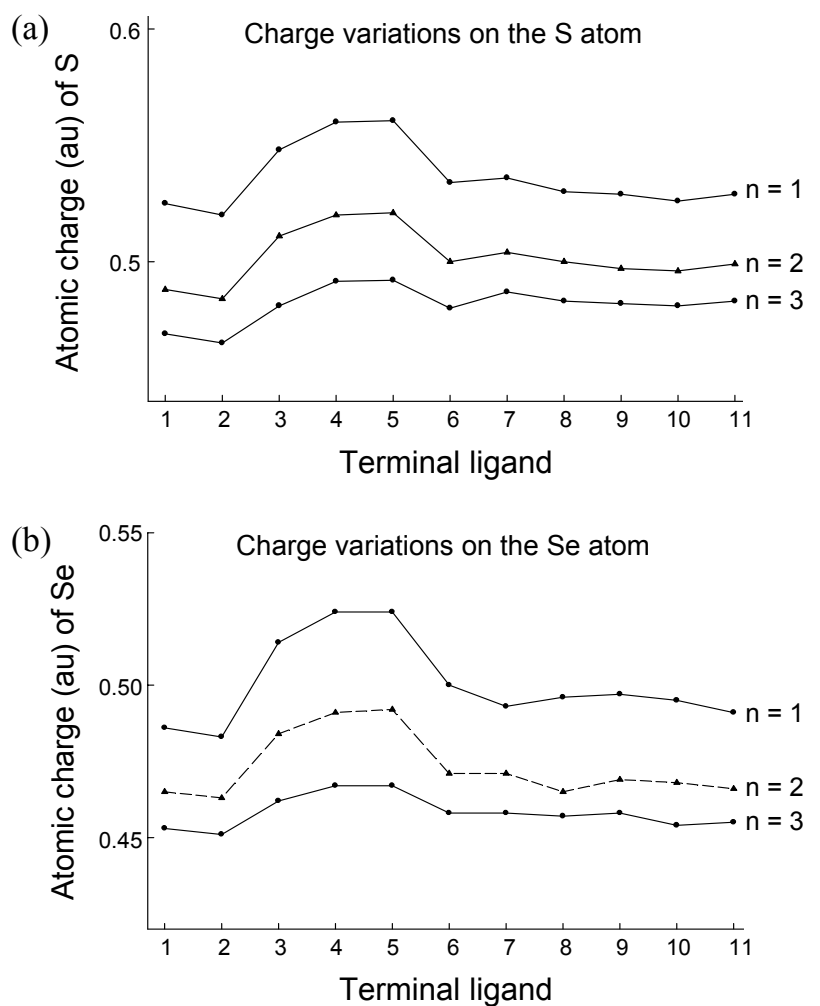

Figure 1. Variations of atomic charges of $\mathrm{X}(\mathrm{S}, \mathrm{Se})$ in $\mathrm{Pd}$ complexes from the electron-donating terminal ligand to electron-withdrawing ligand. $4 \mathrm{NH}_{3}: \mathbf{1}, 4 \mathrm{OCH}_{3}^{-}: \mathbf{2}, 4 \mathrm{PH}_{3}: \mathbf{3}, 4 \mathrm{Cl}^{-}: \mathbf{4}, 4 \mathrm{~F}^{-}: \mathbf{5}, 2 \mathrm{NH}_{3}-2 \mathrm{PH}_{3}: \mathbf{6}$, $2 \mathrm{PH}_{3}-2 \mathrm{Cl}^{-}: 7,2 \mathrm{CH}_{3}-2 \mathrm{PH}_{3}: \mathbf{8}, 2 \mathrm{Cl}^{-}-2 \mathrm{~F}^{-}: \mathbf{9}, 2 \mathrm{CH}_{3}{ }^{-}-2 \mathrm{~F}^{-}: \mathbf{1 0}, 2 \mathrm{OCH}_{3}{ }^{-}$ $2 \mathrm{~F}^{-}: 11$

occupied with bridging phosphine ligands and the other two positions are occupied by terminal ligands. The Pd(II) complexes having thiophene oligomers as bridging ligands, show $\mathrm{S} \cdots \mathrm{S}$ distance ranging from 3.662 to $4.688 \AA$ as shown in the previous paper. ${ }^{10}$ The existence of $\mathrm{S} \cdots \mathrm{S}$ interactions has been stated by various previous theoretical $\left(\mathrm{R}_{\mathrm{S} \cdots \mathrm{S}} \approx 3.38 \sim 4.03 \AA{ }^{11}\right.$ 3.336 to $3.907 \AA^{12}$ ) and experimental ( $\mathrm{R}_{\mathrm{s} . . . \mathrm{s}} \approx 3.212$ to $3.875 \AA \AA^{13}$ 3.33 to $3.98 \AA{ }^{14}$ and $4.027 \sim 4.281 \AA^{15}$ ) works. The existence of several long-range van der Waals interactions along with strong $\mathrm{S} \cdots \mathrm{S}$ interactions which lead to the formation of tubular structures were reported. ${ }^{16}$

Whilst, in Pd(II) complexes with selenophene as bridging ligand, the distance between the Se atoms were $\mathrm{R}_{\mathrm{Se} \cdot \cdots \mathrm{Se}} \approx 3.501 \sim$ $3.810 \AA$. (van der Waals radius of selenium atom is $3.80 \AA$ ) The experimental value conducted by Davis et al. reported the distances (3.716 to $4.197 \AA$ ) between selenium atoms. ${ }^{17}$ The experimental values for the $\mathrm{Se}$ - . Se interactions were $3.78 \AA^{18}$ for the chained structures and 3.42 to $4.72 \AA^{19}$ (3.80 to $4.34 \AA^{20}$ ) for the other experimental studies. Meanwhile, the charge transfer from the electron-donor/electron-withdrawing terminal groups results in more positive and negative atomic charges of the heteroatoms on bridging moiety. The characteristic of terminal ligands has persuaded the trends of the atomic charge of $\mathrm{X}$ as depicted in Figure 1.

As shown in Figure 1, the trends of the charge variation (n) of the sulfur atom are similar to those (m) of the selenium. Due to the electron-property of the terminal ligands, the charge vari- (c)

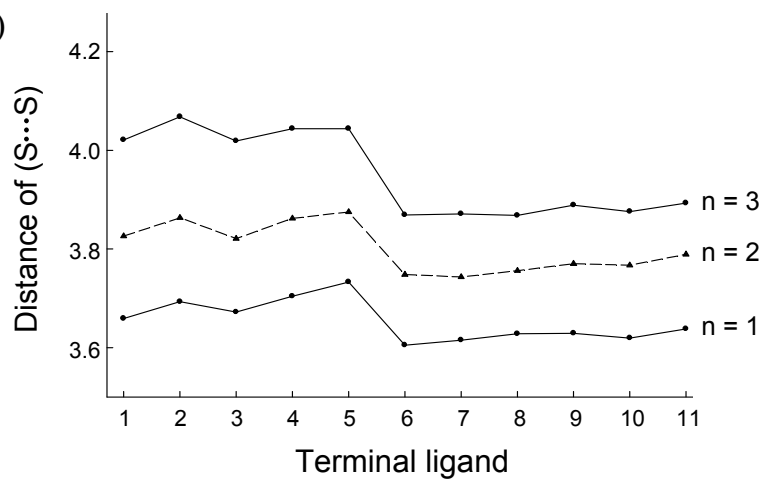

(d)

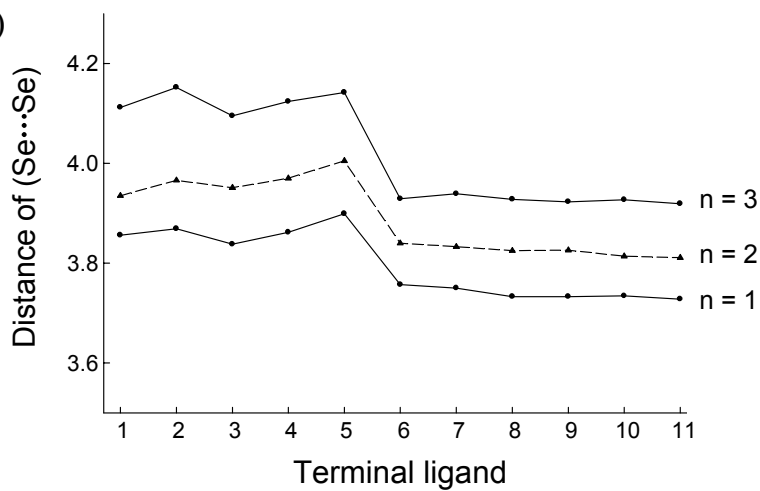

Figure 2. Showing the variations of the $\mathrm{X} \cdots \mathrm{X}$ distances for the thiophene (c) and selenophene (d) bridging ligand in $\mathrm{Pd}(\mathrm{II})$ metal complexes with respect to change in the electron donating and/or withdrawing terminal ligands.

ations of $\mathrm{X}$ were slightly influenced via the metal center. As the unit $(\mathrm{n}=1 \rightarrow 3$ ) of bridging ligand increases, the distance between the terminal ligand and phosphine-substituted thiophene and selenophene oligomers also increases gradually and charge variations on the $\mathrm{S}$ and Se atoms decreases simultaneously. In A type with the electron-donating group, the atomic charges of the $\mathrm{X}(\mathrm{X}=\mathrm{S}, \mathrm{Se})$ atoms are relatively negative, while, in $\mathbf{B}$ type with the electron-withdrawing group, the charges are relatively positive. The atomic charges of the $\mathbf{C}$ type give average level. Moreover, the Pd-P bond lengths are shorter in Pd(II) complexes with the electron-donating terminal ligands than other complexes with the electron-withdrawing terminal ligands. The more charge transfer carried by the Pd atoms of the Pd complexes with thiophene and selenophene bridging ligands also illustrates this enhanced $\pi$-donation.

As shown in Figure 2, the distance between heteroatoms (X) of bridging phosphine-substituted oligomer which can induce attractive/repulsive $\mathrm{X} \cdots \mathrm{X}$ interactions were depended on the property of the terminal ligands. It has been perceived that substitution of the terminal ligand invokes more charge transfer from ligands to the metal centers as evident form stronger bond between the metal and bridging ligand (Pd-P). That is, the charge transfer from the electron-donor/electron-withdrawing terminal groups results in widening the distance between heteroatoms of two bridging moieties. In $\mathbf{A}$ (electron-donator) and $\mathbf{B}$ (electron-withdrawer) types, the distance between heteroatoms (X) of bridging phosphine-substituted oligomer increases. Mean- 
while, the distance in the $\mathbf{C}$ type (one side is electron-donator, the other is electron-withdrawer) is average. With increasing $\mathrm{n}(\mathrm{n}=1 \rightarrow 3)$, the distance of $\mathrm{X} \cdots \mathrm{X}$ increases gradually and the distance from $\mathrm{S}$ to $\mathrm{Se}$ increases simultaneously. That is, the Se'...Se distance of the electron-rich selenophene oligomer containing Pd(II) complexes are longer than those of thiophene oligomer containing Pd(II) complexes.

In conclusion, the present study indicates that nature of terminal ligands have imperative effects on the atomic charge transfer from terminal ligand to heteroatoms (X) and the strength of $\mathrm{X} \cdots \mathrm{X}$ interactions. In the $\mathrm{Pd}(\mathrm{II})$ complexes, the electron-property of terminal ligand well propagated to the heteroatom of bridging ligand via the $\mathrm{Pd}(\mathrm{II})$ metal center. Pd(II) complexes with four electron-donating or four electron-withdrawing terminal ligands showed longer X $\cdots \mathrm{X}$ interactions. Moreover, another important finding of this research work is that $\mathrm{X} \cdots \mathrm{X}$ interactions become stronger on going from $\mathrm{S}$ to Se. This, trend of $\mathrm{X} \cdots \mathrm{X}$ interactions could be related to the electron-retaining ability of heteroatoms. Thus, it could be suggested that $\mathrm{Pd}$ (II) complexes substituted with neutral terminal ligands and having selenophene oligomer as bridging oligomer can activate short $\mathrm{X} \cdots \mathrm{X}$ interactions in this motif of $\mathrm{Pd}(\mathrm{II})$ complexes.

Acknowledgments. This work was supported by the fund of Research Promotion Program (RPP-2010-018), Gyeongsang National University.

\section{References}

1. Akihiko, T.; Takeshi, H.; Tetsuji, M. Tetra. Lett. 2009, 50, 4509.

2. Fichou, D.; Ziegeler, C. In Handbook of Oligo- and Polythiophenes 1999; p 183.

3. Novoa, J. J.; Rovira, M. C.; Rovira, C.; Veciana, J.; Tarrés, J. Adv.
Mater. 2004, 7, 233.

4. Phetmung, H.; Buatong, N.; Chotekeaw, P.; Pakawatchai, C. J. Am. Chem. Soc. 2000, 111, 8622.

5. Hayashi, S.; Nakanishi, W. A.; Furuta, J.; Drabowicz, T.; Sasamoric, T. Tokitoh, N. New J. Chem. 2009, 33, 196.

6. Mont, W.; Bätcher, M.; Daniliuc, C.; Devillanova, F.; Druckenbrodt, C.; Jeske, J.; Jones, P.; Lippolis, V.; Ruthe, F.; Seppälä, E. Eur. J. Inorg. Chem. 2008, 29, 4562.

7. Hudhomme, P.; Soazig, L. M.; Durand, C.; Nuira, G.; Nicolas, M.; Eric, L.; Magali, A.; Alain, G.; Riou, A. Chem. Eur. J. 2001, 7, 5070.

8. Becke, A. D. The challange of $d$ - and f-Electrons: Theory and Computation, ACS Symposium Series, No. 394; Salahub, D. R., Zerner, M. C., Eds.; American Chemical Society: Washington D. C., 1989; p 166.

9. Lee, C.; Yang, W.; Parr, R. G. Phys. Rev. 1988, B37, 785.

10. Arooj, M.; Kim, K. H.; Kim, D. H.; Kim, B. S.; Park, G. Y.; Jeong, S. H.; Shin, S. C.; Park J. K. Bull. Korean Chem. Soc. 2009, 30, 3079.

11. Christian, B.; Werz, D. B.; Horst, K.; Gleiter, R. J. Am. Chem. Soc. 2006, $128,2666$.

12. Werz, D. B.; Fischer, F. R.; Stefan, C. K.; Frank, R.; Gleiter, R. J. Org. Chem. 2008, 73, 8021.

13. Brusso, J.; Owen, P. C.; Robert, C. H.; Mikhail, E. I.; Richard, T. O.; John, F. R. J. Am. Chem. Soc. 2004, 126, 8256.

14. Williams, J.; Mark, A. B.; Hau, H. W.; Peter, C. W. L.; Thomas, J. E.; Urs, G.; Douglas, C. Acc. Chem. Res. 1985, 18, 261.

15. Wei, Y.; Tian, H.; Yanhou, G.; Fosong, W. Cryst. Growth Des. 2008 , 7, 2352.

16. Werz, D. B.; Gleiter, R.; Frank, R. J. Am. Chem. Soc. 2002, 124, 10638.

17. Davis, W.; Hickesr, O.; Oakley, I.; Hao, B. Can. J. Chem. 1993, 71, 180.

18. Asit, Patra, Wijsboom, Y.; Leitus, G.; Bendikov, M. Org. Lett. 2009, 11, 1487.

19. Armand, P.; Dexpert, I. H.; Bittencourt, D.; Raoux, D.; Philippot, E. J. De Physique. 1992, IV. 2, C2-189.

20. Alberth, L.; Christan, B.; Frank, R.; Rolf, G. Eur. J. Org. Chem. 2009, 17, 2765. 